\title{
Letter from the Editorial Board
}

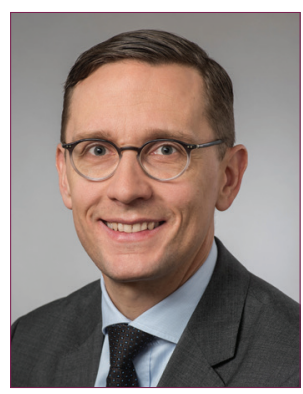

\begin{abstract}
Joachim R Ehrlich
Joachim R Ehrlich MD is currently Head of Cardiology and Electrophysiology at St Josefs-Hospital, Wiesbaden, Germany. He completed his internship and residency training in medicine in 2001 at Goethe-University, Frankfurt, Germany and gained a fellowship in basic cardiac electrophysiology at the Montreal Heart Institute, Montreal, Canada. Following a fellowship in cardiology at Goethe-University, Dr Ehrlich gained German Cardiac Society certifications in interventional cardiology and electrophysiology in 2014. Dr Ehrlich has specific scientific expertise in basic cardiac electrophysiology, with a focus on atrial fibrillation research. He is also highly experienced in pharmacological management of cardiac arrhythmias, oral anticoagulation, cardiac resynchronisation therapy, genetically determined cardiac arrhythmia syndromes and risk stratification for sudden cardiac death. Dr Ehrlich is a Fellow of several scientific organisations, including the American Heart Association, the Heart Rhythm Society, the European Heart Rhythm Association and the European Society of Cardiology, among others. He is on the editorial boards of several scientific journals, including Heart Rhythm, the Canadian Journal of Cardiology and the European Journal of Arrhythmia \& Electrophysiology.
\end{abstract}

Citation: European Journal of Arrhythmia \& Electrophysiology. 2018;4(1):9

\section{Dear Colleagues,}

W

I hope that you will enjoy reading the selection of articles in this issue, which all offer insights into a range of pertinent topics in the arrhythmia and electrophysiology arenas. First, we have an interesting and timely editorial from Haran Burri, on the use of smartphones and smartwatches in screening for atrial fibrillation. Next, we have an original research article from Erik Wissner and colleagues, who have conducted a study comparing invasive activation and phase mapping to noninvasive phase mapping in patients with cavotricuspid isthmus-dependent atrial flutter using a novel noninvasive epicardial and endocardial electrophysiology system.

This edition also features a number of case reports, ranging from a study of a case of intermittent left bundle branch block from Muhammad Ameen, a case of normalised left ventricular systolic function in dilated cardiomyopathy after cardiac contractility modulation therapy from Laurens Bon et al., to a case of pseudoseizure with pseudo-ventricular tachycardia by Ozlem Karabulut et al.

We are currently welcoming submissions to our autumn edition and we encourage readers to submit reviews, original research, case reports and editorials. Submissions can be made through our online submission system at: www.editorialmanager.com/touchcardio or by contacting the journal's Managing Editor (E: nicola.cartridge@touchmedicalmedia.com).

We hope that you enjoy reading this edition and, as always, we welcome your feedback and comments on any of our articles or content on the touchCARDIO.com site.

\section{Joachim R Ehrlich}

on behalf of the Editorial Board and touchCARDIO team 